\title{
Factors affecting students' intentions to use a university bus: Importance of travel attitudes and service quality attributes
}

\author{
Muhammad Ashraf Javid* and Ghadeer Hamed Al-Kasbi \\ Department of Civil and Environmental Engineering, University of Nizwa, Birkat-al-Mouz, 616, Nizwa, Oman \\ * Corresponding Author: ma.javid@hotmail.com
}

Submitted : 15/02/2020

Revised :23/11/2020

Accepted : 19/12/2020

\begin{abstract}
This paper aims to assess the student's perceptions concerning to characteristics of a university bus service and private car. A questionnaire was designed consisting of personal and travel characteristics of the respondents, respondent's responses on the importance of various service qualities attributes, and mode choice characteristics. The total collected samples were 314 comprising of university students. The relaxed traveling, travel time saving, safety and privacy, and freedom and flexibility in traveling are significant characteristics of travel alternatives. Most of the students believe that traveling in a car gives them more freedom and flexibility in traveling. Traveling in a car is expensive, and students feel happy and relaxed while traveling on a university bus as compared to a car. Car-oriented and bus-oriented attitudes are also significant in determining the students' intentions toward the university bus service considering their pro-social elements. These findings will help make improvements in the bus service seeking the students' preferences.
\end{abstract}

Keywords: Mode choice; Travel behavior; Public transport; Private transport, Questionnaire.

\section{INTRODUCTION}

The urban population of Oman is increasing day by day and resulting in increased travel demand on road infrastructure. The private vehicle ownership and usage is also increasing as the main mode of commuting for most of the residents is a private car and taxi service. At present, there is a growing need for public transport in Oman to stimulate economic development, increase road safety, and combat traffic congestion and environmental problems. The Government of Oman needs to focus on a range of public policy issues related to the development and promotion of public transport facilities such as public and private partnerships, and regularization of various modes of transport. People recognize the need for a better transport system, but their knowledge and experience of different modes of transport is very limited. The attitude of people towards the use of public transport is positive; however, their preference for the use of private cars is more apparent as it provides more flexibility, privacy, and freedom in traveling (Belwal, 2013). The use of public transport is very limited. Only $1.3 \%$ of the population uses buses, while the rest depend on private transport or taxis only (Belwal, 2013). People prefer public transport for long-distance travel and desire large buses or trains for this purpose. Public transport is acceptable to those residents, who currently spend less 
than 20 OMR per month on transportation. The relationship between the use of public transport and income is evident. Almost, a quarter of the residents need public transportation daily and sees it as well comfortable and economical. However, hot climate, safety, females' hesitation to share rides with the male, status consciousness, and addiction to cars are the major barriers in the promotion of public transport. Belwal (2013) reported that public transport infrastructure, priority transport for working-class and females, accessible public transport services for people belonging to different socioeconomic groups, awareness, and promotion, and marketing and behavior modification programs are the main elements of improvement in the public transport sector.

Belwal et al. (2013) have reported that many factors affect the attitudes of the public toward public transport services and suggested many policy implications based on the findings. These factors included traveler's personal information, transportation infrastructure characteristics, travel incentives, and disincentives, and level of service quality of the offered travel alternatives. Socioeconomic demographic (SEDs), situational constraints, individual travel attitudes and personality traits, social, subjective and personal norms also play a significant role in defining the attitudes of the people with transportation modes (Javid et al., 2016; Javid et al., 2015a). The cultural factors, local environment, and vehicle ownership trends and its usage greatly influence the mode choice behavior of the travelers. It is vital to explore such aspects of the mode choice behavior of the commuters in the local context of Oman as it has unique cultural, social, and economic characteristics. The infrastructural characteristics and specific travel attitudes and preferences play a significant role in shaping people's travel behavior patterns. Students make a significant part of the travel market in any society and their travel preferences significantly differ from other segments. It is required to assess the significant factors that influence their mobility needs and travel intentions. This paper aims to identify the significant factors concerning the mode choice behavior of university students taking the University of Nizwa (UoN) as a case study. A questionnaire survey was designed and conducted with the UoN students and important factors of service quality from mode choice perspectives were identified. The collected data were analyzed using factor analysis and structural equation modeling methods. The remainder of the paper is organized in the following manner. Relevant literature is presented in section 2. The research methods are presented in section 3. The survey and analysis results are discussed in section 4. Conclusions and recommendations are presented in the last section.

\section{LITERATURE REVIEW}

There is a difference of opinion among university students in the way of their needs and mobility. The travel characteristics and preferences of the students differ significantly from other groups of the travel market. Sometimes their travel behavior is determined by the socioeconomic status of their parents and/or guardians. The university students relatively belong to the low-income category of the population and their travel behavior is typically different from other groups of travel market (Khattak et al., 2011). The analysis of the travel behavior of university students found a significant variation in travel patterns for the students who are generally resident on campus and off campus (Maneesh, 2007). Volosin (2014) found that that student travel designs change considerably from those of the rest of the populace.

Those students who own a private car mostly prefer to drive, while those who do not have a car rely on other modes of travel. For example, they may travel as a passenger with friends or may take a campus bus (Limanond et al., 2011). Availability of car, trip duration, and day of travel, weather condition, trip purpose, trip origin location, and accessibility are supposed to have good predictors of students' mode choice (Romanowska et al., 2019; Klöckner and Friedrichsmeier, 2011). The level of service quality at bus stops and in buses, cleanliness, reliability, bus frequency, and safety and crew service are strongly related to the mode choice pattern (Shaaban and Kim, 2016). Modal choices are influenced by travel time, income, and marital status (Henning et al., 2019). Travel distance, cost and time, comfort in traveling, age, gender, and vehicle ownership are the most important factors influencing the mode choice of the students (Soman and Verghese, 2019; Kotoula et al., 2018; Nasrin, 2017, Das et al., 2016; 
Bicikova, 2014). The family income, travel time, and the parent education level are the main attributes in determining the mode choice behavior of the students (Assi et al., 2018). The travel choices are affected by a combination of cost, attitudes, and roadside environment (Whalen et al., 2013). Guzman and Diaz (2005) found that travel time, travel taken a toll, and comfort are the key determinants of students' mode choice. Situational factors, individual attitudes, personality traits, status consciousness and flexibility, and freedom in traveling also have a significant influence on the travel behavior of a particular group of travel market (Javid et al., 2015b; Belwal, 2013).

Comfort, privacy, independence, flexibility, efficiency, security, recreation, economy, unavailability of public transport, accessibility, family responsibilities, tradition and custom, passion for driving, climatic conditions, habitual nature, special needs, and the taxi-phobia are the pressing reasons for using a private car (McLaughlin, 2016). Continuous development of near-campus areas results in shifts in the location of residence of off-campus students and thus results in higher transit traffic (Ripplinger et al., 2009). Students having friends and classmates increase the odds of taking public transport (Zhou, 2012). Zhou (2016) found that proper access to bus service and a subsidized transit pass can help in promoting the use of non-driving-alone modes e.g. bus service, carpooling, etc., and travel time is significantly associated with travel behavior. It is believed that home-to-school distances are negatively related to daily transit trips (Daisy et al., 2018). Cattaneo et al. (2018) explained that the students are influenced by their travel experience and the cultural framework in which they are surrounded. The sustainability of transportation has a direct relationship with the improvement of urban environmental quality. Promotion in public transport and a reduction in the number of private cars can help in reducing the level of emissions (Haider et al., 2018). This is only possible through the development of pro-social travel attitudes among the public inducing the students who make a good share of daily travel demand. Service reliability and comfort and driver's compliance with traffic rules and driving habits have a significant influence on student's intentions to use a university bus (Javid et al., 2020). The literature has paid small attention to students' travel behavior in this part of the world where socioeconomic, transportation infrastructure, cultural, and religious characteristics greatly differ from other parts of the world. It demands to investigate of the influencing factors of the mode choice of the university students.

\section{RESEARCH METHODS}

\section{Questionnaire Design}

A questionnaire was designed to achieve the objectives of this study. This questionnaire consisted of three parts. In the first part of the questionnaire, students were asked to report their personal and travel information, for example, gender, marital status, age, nationality, possession of a driving license, traveling mode to university/home, travel time and cost, etc. In the second part of the questionnaire, some attributes of service quality of travel alternatives were chosen to learn the perceptions of the student about commuting. This part was designed to know the level of importance of the students with some service quality dimensions such as saving of travel time and costs, privacy while traveling, safety while traveling, flexibility in the travel schedule, flexibility in route, independent and relaxed traveling. All questions in part 2 were evaluated using a five-point Likert scale: not important at all (1), slightly important (2), moderate (3), important (4), and very important (5). This five-point Likert-type ordinal scale was chosen considering the reliability and normality of the data. In the third part, the students were asked to give the best choice for each phrase using the five-point Likert scale, i.e., strongly disagree (1), disagree (2), neutral (3), agree (4), and strongly agree (5). The main theme behind the design of these statements included the following: prefer to use a car, because it saves their time, the car provides flexibility in traveling, traveling on a car is more comfortable than the bus, it is expensive to travel on car, have to wait for a long time for university bus, use university bus because it is cheaper than a car, feel happy when traveling with friends on the bus, prefer to use university bus as it is safer than the private car, and it is a moral obligation to use university bus as it will reduce traffic problems and save natural resources. All the survey items were designed considering the target group of the respondents. It was hypothesized 
that these important service quality attributes would have a significant influence on student's intentions to choose a travel mode.

\section{Selection of Survey Location and Sample Size}

The survey was conducted in Nizwa with the students of the University of Nizwa (UoN) because it was easy to approach the target population. The sample of the survey consisted of students from the UoN who lived on campus and also off-campus. Most of these students either use university bus service for daily commuting or use their private cars. It was hypothesized that the target students would provide a good representation of the population. There are many studies conducted in many areas with different sample sizes. In this study, the sample size was determined to take into account the target population and the methods of data analysis. This sample size was decided considering the requirements of sample size for use in Structural Equation Modeling (SEM) analysis. A minimum of 200 samples is required to reduce biases in the data and analysis (Boomsma and Hoogland, 2001; Kline, 2005). Other researchers have said that the minimum sample size should be at least ten times the number of free parameters (Golob, 2001, Raykov and Marcoulides, 2000). It was decided to obtain a minimum of 300 samples to make a significant analysis. A random sampling strategy was used in distributing the questionnaire to each category of students, e.g. undergraduate, master and diploma students. A self-completion approach was used in obtaining the student's responses. The students were given ample time to complete the questionnaire. The completed questionnaires were collected back after the due time.

\section{Data Analysis Methods}

The collected data were analyzed using multivariate statistical methods. Exploratory factor analyses were conducted on students' responses. The extracted factors were named seeking the nature of their observed variables or indicators. A cut-of-value of 0.5 was used in the extraction of factors. This extraction was done using the Maximum Likelihood (ML) method and varimax rotation. The rotation was carried out to obtain more logical and interpretable factors. Cronbach's alpha values were estimated to check the reliability of survey results and extracted factor. A Cronbach's Alpha value of more than 0.5 shows a moderate level of the reliability of the extracted factors and internal consistency among respondents in the evaluation of the observed variables (Taber, 2017; Field, 2009). The calculated values were compared with the recommended values of Cronbach's alpha. The results of factor analyses were used to construct the structure of students' intentions to use university bus service under different scenarios. This was done using the concept of Structural Equation Modeling (SEM) which is a multivariate statistical analysis tool. This approach has many merits on conventional regression analysis. It allows the researchers to include multiple observed and unobserved (latent) variables in a single model, and interpret the direct and indirect effects between the variables. A hypothetical structural model of this study is presented in Figure 1. This model states that the extracted factors or latent variables of service quality attributes and travel attitudes affect students' intentions to use university buses. Eq. (1) shows a typical structural equation. The reliability of the constructed model is checked by comparing indices of the goodness of fit parameters with their recommended values. These parameters included the ratio of chi-square to the degree of freedom (chi-sq./DF) [should be between 2-5], comparative fit index (CFI) [>0.9], goodness of fit index (GFI) [>0.9], adjusted goodness of fit index (AGFI) [>0.9], and Root mean square error of approximation (RMSEA) [<0.08] (Bentler \& Bonett, 1980; Hooper et al., 2008; Schermelleh-Engel et al., 2003).

$$
\eta=\sum_{i=1}^{n} \beta_{i} X_{i}+\sum_{j=1}^{n} Y_{j} \gamma_{j}+\varepsilon
$$

where 
$\eta=$ endogenous observed variable

$X_{i}=$ exogenous latent variables in the model, $i=1,2, \ldots \ldots, n$

$\beta_{i}=$ structural coefficients for exogenous latent variables, $i=1,2, \ldots \ldots, n$

$Y_{j}=$ exogenous observed variables of personal characteristics, $j=1,2 \ldots \ldots n$

$\gamma_{j}=$ structural coefficients for exogenous observed variables of personal characteristics, $j=1,2 \ldots \ldots . n$

$n=$ number of significant observed/latent variables in the structural models

$\varepsilon=$ errors associated with observed variables

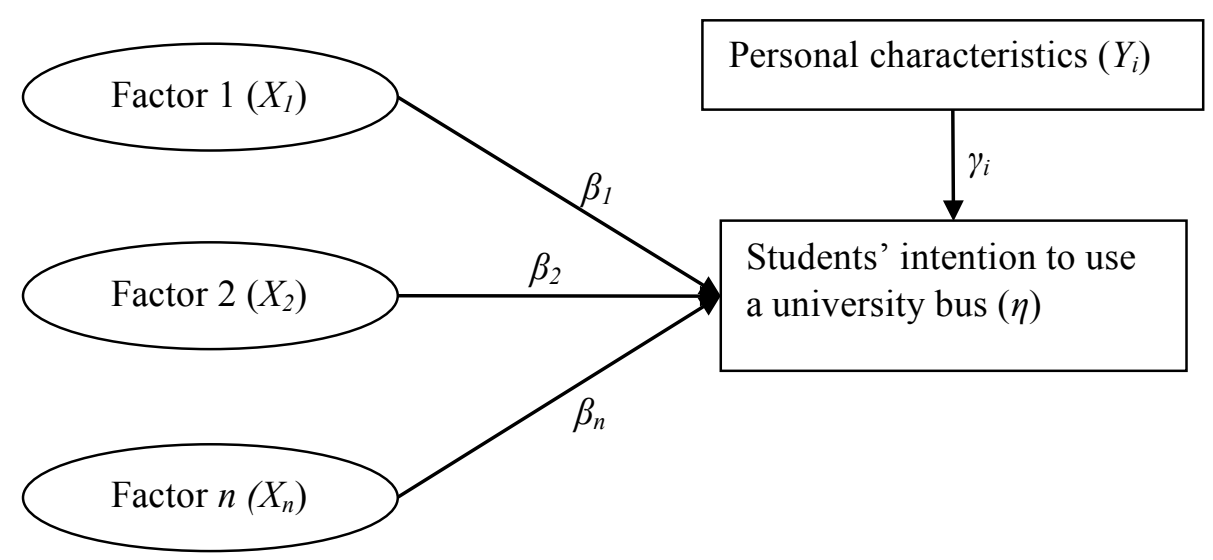

Figure 1. A hypothetical structural model.

\section{RESULTS AND DISCUSSION}

\section{Description of Respondents Personal and Travelling Characteristics}

A total of 314 samples were obtained from the survey locations. The descriptive statistics of the sample are shown in Table 1 . Almost $63 \%$ of the respondents are females, which is very much consistent with the actual share of female students within the campus. Around $84 \%$ of students are married, and $16 \%$ of the students are single. Out of 314 respondents, $63 \%$ of the respondents are in the age of (20-25 years), $22 \%$ are less than 20 years old and $9 \%$ are in 25-30 years. The rest for the student aged above 30 years. The distribution in Table 1 shows that $49 \%$ of the respondents have a driving license, and 51\% of them don't have a driving license. Students who have a personal car are $35 \%$ and the students who do not have a personal car are $65 \%$.

Table 1. Description of respondents' personal and travel characteristics.

\begin{tabular}{|l|l|}
\hline Characteristics & Distribution (\%) \\
\hline Gender & Male (37\%), Female (63\%) \\
\hline Marital status & Single (84\%), Married (16\%) \\
\hline
\end{tabular}




\begin{tabular}{|l|l|}
\hline Age (years) & Under 20 (22\%), 20-25 (63\%), 26-30 (9\%), above $30(6 \%)$ \\
\hline Nationality & Omani (80\%), Expats $(20 \%)$ \\
\hline Personal income & No income (45\%), below 100 OR (33\%), above 100 OR (22\%) \\
\hline Driving license & Yes (49\%), No (51\%) \\
\hline Personal car ownership & Yes (35\%), No (65\%) \\
\hline $\begin{array}{l}\text { Usual traveling mode to } \\
\text { university }\end{array}$ & Car / taxi (43\%), university bus (57\%) \\
\hline
\end{tabular}

\section{Distribution of Responses on Attributes of Service Quality and Preferences}

Figure 2 shows the statement along with their level of importance. It shows that the most important attributes of mode selection for the students are relaxed traveling, safety during the traveling, and travel time-saving. The driving task generally puts an extra burden and sometimes results in stress on the drivers. This extra burden and stress may put students in danger while driving a private car to the university. Traveling on a bus provides relaxed and safe traveling in comparison to private transport. Figure 3 shows the opinions about the traveling mode and student's level of agreement with different traveling related attitudes and preferences. The students have a high level of agreement with the following statements i.e. I prefer to use it because it saves my travel time, traveling by car is more comfortable than the bus, and car provides me more flexibility in traveling. It is agreed that the car provides more

Relaxed travelling such as a passenger Independent / alone travelling Flexibility of travel route Flexibility in travel schedule Safety during travelling Privacy during travelling Travel cost saving Travel time saving

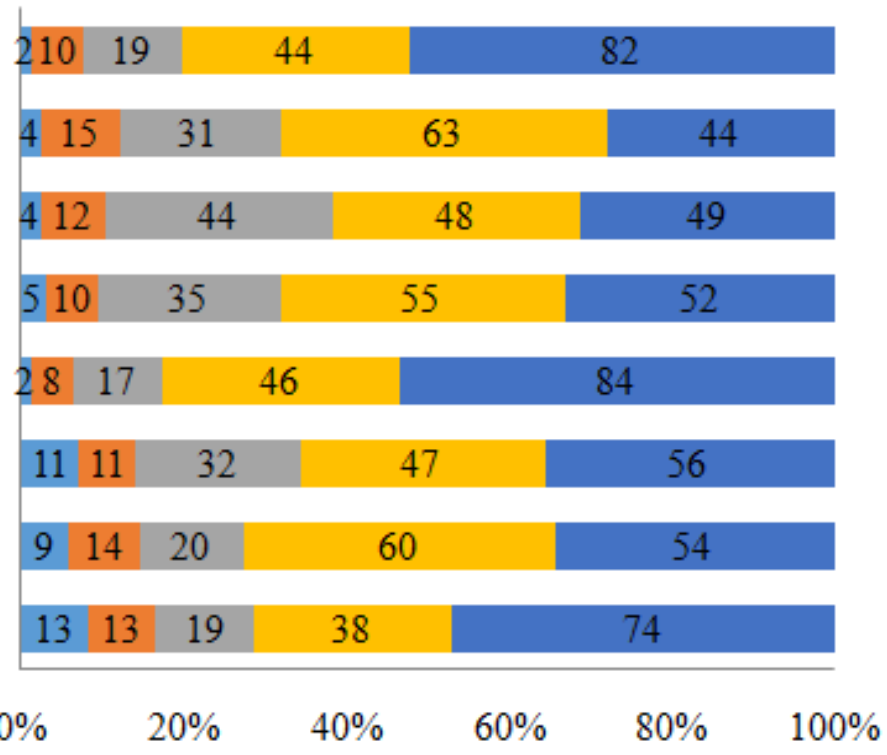

- Not at all important - Important
Slightly Important

Very Important
- Moderately Important 
Figure 2. Distribution of respondent's responses on important service quality attributes.

I feel that it is our moral obligation to use university bus as it will save natural resources.

I feel that it is our moral obligation to use university bus as it will reduce traffic problems.

Even I have a car I would prefer to use university bus as it is safer than private car.

I feel happy when I travel with my friends on bus.

I use university bus because it is cheaper than car.

I have to wait for long time for university bus.

It is expensive to travel on car.

Travelling on car is more comfortable than bus.

Car provides me flexibility in travelling.

I prefer to use car because it saves my time.

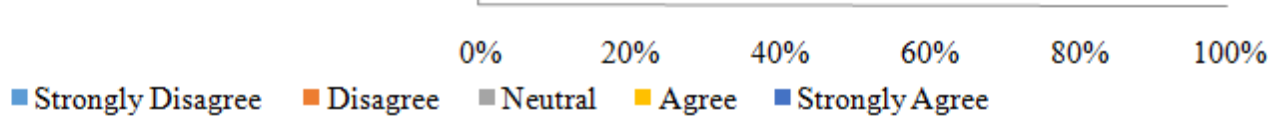

Figure 3. Distribution of responses on preferences in the travel mode selection.

flexibility and comfort in traveling than public transport modes (Javid et al., 2016; Steg, 2005). These results in Figure 3 show that the use of buses tends to increase travel time and reduce freedom in traveling. On the contrary, traveling in a car is expensive and students feel happy and relaxed while traveling on the university bus as compared to a car. More than $50 \%$ of the students agreed that we should use the university bus for the reduction of traffic demand and consumption of natural resources. Such trends of students' intentions help in deriving the environmentally friendly and pro-social travel policies concerning students.

\section{Factor Analysis on Survey Data}

An exploratory factor analysis (EFA) was conducted on students' responses to the importance of the selected service quality attributes. A cut of point value 0.5 of factor loading was used for this extraction. Any observed variable having factor loading or regression weight less than 0.5 were excluded from the analysis. This factor analysis resulted in three factors as presented in Table 2. These three factors were assigned a specific name considering the nature of their observed variables and most influencing observed variables. The observed variables with higher factor loadings have more significance and influence in explaining the corresponding factor or latent variable. The average score on the five-point scale of each observed variable is also presented in Table 2. The three extracted factors are (1) saving and comfort in traveling (SCT), (2) flexibility and freedom in traveling (FFT), and (3) safety and privacy in traveling (SPT). The estimated values of Cronbach's alpha are also presented in Table 2 of each factor. These values are more than 0.5 which shows good reliability of the factors and consistency among respondents in evaluating the observed variables (Taber, 2017; Field, 2009). The variance explained by SCT, FFT, and SPT is $27.708 \%, 25.075 \%$, and $17.798 \%$, respectively. The first factor of SCT included observed variables on travel cost and time-saving and 
relaxed traveling. This factor shows that the students have placed high importance on less generalized travel cost, and comfort in traveling. Such kinds of students would choose a travel mode that satisfies their requirements. The second factor of FFT shows that the respondents prefer a mode which offers flexibility in the choice of route and travel schedule. These students' perceptions are consistent with the offered service quality of a private car that provides a higher level of flexibility in the selection of a travel route as well as schedule (Beirao and Cabral, 2007; Steg, 2005; Anable, 2005). Those students who possess a strong belief in such aspects of traveling would not prefer to use the university bus. The third factor of SPT shows that the students have given high importance to safety and privacy in traveling, and this importance level would affect their choice of mode.

Table 2. Rotated factor loadings for the level of importance on selected service attributes.

\begin{tabular}{|c|c|c|c|c|}
\hline \multirow[b]{2}{*}{ Observed variables } & \multirow[b]{2}{*}{ Mean } & \multicolumn{3}{|c|}{ Factors } \\
\hline & & $\begin{array}{c}\text { Saving and } \\
\text { Comfort in } \\
\text { Travelling (SCT) }\end{array}$ & $\begin{array}{c}\text { Flexibility and } \\
\text { Freedom in } \\
\text { Travelling (FFT) }\end{array}$ & $\begin{array}{c}\text { Safety and } \\
\text { Privacy in } \\
\text { Travelling (SPT) }\end{array}$ \\
\hline Travel cost saving (SCT-1) & 3.886 & 0.828 & & \\
\hline Travel Time saving (SCT-2) & 3.936 & 0.762 & & \\
\hline Relaxed travelling (SCT-3) & 4.235 & 0.510 & & \\
\hline Flexibility of travel route (FFT-1) & 3.801 & & 0.792 & \\
\hline Flexibility in travel schedule (FFT-2) & 3.885 & & 0.656 & \\
\hline Independent traveling (FFT-3) & 3.815 & & 0.563 & \\
\hline Safety during traveling (SPT-1) & 4.286 & & & 0.934 \\
\hline Privacy during traveling (SPT-2) & 3.805 & & & 0.575 \\
\hline \multicolumn{2}{|c|}{$\%$ of variance explained } & 27.708 & 25.075 & 17.798 \\
\hline \multicolumn{2}{|c|}{ Cronbach's value $(\alpha)$} & 0.728 & 0.698 & 0.677 \\
\hline
\end{tabular}


Another EFA was conducted on students' responses related to their preferences in the trip making. This factor analysis resulted in two factors and these factors were named seeking the tendencies of their associated observed variables as presented in Table 3. These two factors are (a) car-trendy attitudes (CA) and bus-trendy attitudes (BA). The variance explained by CA and BA is $31.512 \%$ and $25.409 \%$, respectively. The estimated values of Cronbach's alpha for bother factors are more than 0.5 which presents a moderate level of reliability. The factor of CA shows that the students prefer to use a car as it saves their time and gives them more flexibility and comfort in traveling. The students who possess such attitudes would continue to use the private car over the university bus service. The factor loadings of the BA factor depict that students feel happy when they travel on university buses as they can interact with their friends and increase social interactions. Also, a university bus provides them a cheap mode of travel. These results imply that those students who like to interact with other people in traveling and prefer cheap travel option would continue to use the university bus.

Table 3. Rotated factor loadings for preferences in traveling.

\begin{tabular}{|c|c|c|c|}
\hline \multirow[b]{2}{*}{ Observed variables } & \multirow[b]{2}{*}{ Mean } & \multicolumn{2}{|c|}{ Factors } \\
\hline & & $\begin{array}{c}\text { Car-trendy } \\
\text { attitudes (CA) }\end{array}$ & $\begin{array}{c}\text { Bus-trendy } \\
\text { attitudes (BA) }\end{array}$ \\
\hline I prefer to use a car because it saves time. (CA-1) & 4.274 & 0.845 & \\
\hline The car provides me flexibility in traveling. (CA-2) & 4.121 & 0.782 & \\
\hline Traveling in a car is more comfortable than a bus. (CA-3) & 4.353 & 0.673 & \\
\hline I feel happy when I travel with my friends by bus. (BA-1) & 3.598 & & 0.631 \\
\hline I use a university bus because it is cheaper than a car. (BA-2) & 3.204 & & 0.563 \\
\hline It is expensive to travel in a car. (BA-3) & 4.286 & & 0.515 \\
\hline \multicolumn{2}{|c|}{$\%$ of variance explained } & 31.512 & 25.409 \\
\hline \multicolumn{2}{|c|}{ Cronbach's value $(\alpha)$} & 0.809 & 0.556 \\
\hline
\end{tabular}

\section{Structural Model of Students' Intentions}

Three structural models were developed using the results of factor analysis. The influence of extracted factors was identified on objective variables related to the use of university buses and private cars. Three objective variables 
were defined from the questionnaire survey; for example, (1) even I have a car I would prefer to use the university bus as it is safer than a private car, (2) I feel that it is our moral obligation to use university bus as it will reduce traffic problems, and (3) I feel that it is our moral obligation to use university bus as it will save natural resources. These variables were included in the model on five-point Likert scales that were used in the evaluation. Some observed variables on personal and travel characteristics of students were defined to include in the model but most of those variables did not find any significant structural relationship in the model. The only observed variable of 'possesses a driving license' was found significant and included in the model. The insignificant variables are not mentioned in Figure 4 as well as in Table 4. A typical structural model is shown in Figure 4. The structural relationships of SCT, FFT, and BA with a variable of 'even I have a car I would prefer to use university bus as it is safer than a private car' are significant either at a $1 \%, 5 \%$, or $10 \%$ level of significance. The negative relationship of SCT with variable shows that those students who have high importance for travel time saving and comfort in traveling would not prefer to use university bus service once they have a private car. Such students believe that the car is more comfortable and helps in saving travel costs and time as compared to the university bus service. The negative structural coefficient of FFT and BA with the variable of 'even I have a car I would prefer to use university bus as it is safer than private car' show that those students who have high beliefs in freedom and flexibility of travel mode would not prefer to use the university bus over a car as the use of bus would restrict their freedom and flexibility in traveling. This is true, as the schedule and route of the bus service are fixed, and students would have little freedom in their traveling. The students who possess bus trendy attitudes would prefer to use the university bus service even if they have a car as indicated from the positive structural coefficient of BA with a variable of 'even I have a car I would prefer to use university bus as it is safer than a private car'. It implies that to promote the use of the university bus among students it is required to develop transit-oriented attitudes among them. Those students who possess a driving license will not prefer to use university bus service as the structural relationship is negative. Daisy et al. (2018) have also reported that auto trips are positively associated with those students who have a driving license. The values of the goodness of fit parameters are falling within the permissible limits or near to the recommended values which show that this model has good predictability of students' intentions to use the university bus service.

Table 4 shows the results of structural modeling for the students' pro-social travel behavior. In these two models, students' intentions to use the university bus service were determined considering two social aspects of traveling i.e. moral obligation to use a bus for the reduction in traffic problems and moral obligation to use a bus for the conservation of natural resources. The FFT latent variable has a negative and significant relationship with the variable of 'I feel that it is our moral obligation to use university bus as it will reduce traffic problems'. It shows that those students who believe in offered freedom and flexibility of auto mode would not prefer to consider the use of the university bus service even for the reduction of traffic congestion. This might be true as at present there is no serious issue of traffic congestion and such attitudes might change once the real congestion events happened. Those students who have bus-oriented attitudes would prefer to use the bus service considering the scenario of traffic congestion reduction. However, the students with a driving license would continue to use their private cars. The nature and impact of FFT, BA, and driving license possession variables on the variable of 'I feel that it is our moral obligation to use university bus as it will save natural resources' are the same as with the variable of 'I feel that it is our moral obligation to use university bus as it will reduce traffic problems'. The additional significant structural relationship of CA is with the variable of 'I feel that it is our moral obligation to use university bus as it will save natural resources'. This positive relationship shows that even students have car-oriented attitudes still they feel morally obliged to use the university bus service for the conservation of natural resources. It predicts pro-social behavior among some of the university students. The indices of the goodness of fit parameters show that these structural modeling results have an acceptable level of reliability in predicting the students' travel behavior. 


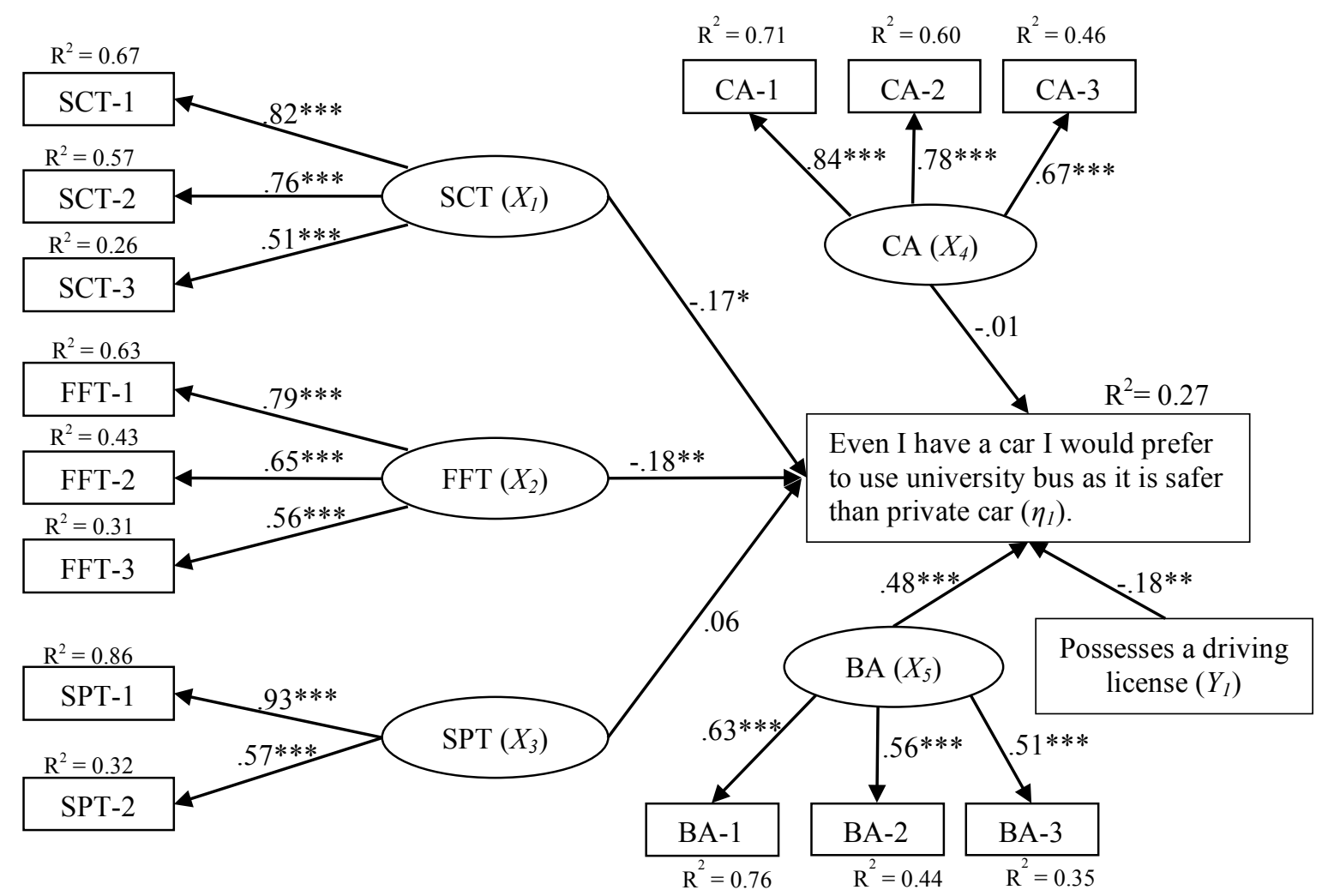

Significant at $1 \%, * *$ significant at $5 \%, *$ significant at $10 \%$

Chi-sq. $/ \mathrm{DF}=2.558, \mathrm{CFI}=0.806, \mathrm{GFI}=0.855, \mathrm{AGFI}=0.791, \mathrm{RMSEA}=0.10$

Figure 4. A structural diagram of student's perceptions.

Table 4. Standardized estimates of structural equations for respondents' preferences.

\begin{tabular}{|l|c|c|}
\hline \multicolumn{1}{|c|}{ Observed / Latent variables } & $\begin{array}{c}\text { I feel that it is our moral } \\
\text { obligation to use a } \\
\text { university bus as it will } \\
\text { reduce traffic problems } \\
\left(\eta_{2}\right)\end{array}$ & $\begin{array}{c}\text { I feel that it is our moral } \\
\text { obligation to use a } \\
\text { university bus as it will } \\
\text { save natural resources } \\
\left(\eta_{3}\right)\end{array}$ \\
\hline Saving and Comfort in Travelling (SCT) - $\left(X_{1}\right)$ & $\beta_{1}=-0.07$ & $\beta_{1}=-0.01$ \\
\hline Freedom and Flexibility in Travelling (FFT) - $\left(X_{2}\right)$ & $\beta_{2}=-0.13^{*}$ & $\beta_{2}=-0.22^{* *}$ \\
\hline Safety and Privacy in Travelling (SPT) - $\left(X_{3}\right)$ & $\beta_{3}=-0.02$ & $\beta_{3}=-0.15^{*}$ \\
\hline Car-trendy attitudes $(\mathrm{CA})-\left(X_{4}\right)$ & $\beta_{4}=0.07$ & $\beta_{4}=0.11^{*}$ \\
\hline Bus-trendy attitudes (BA) - $\left(X_{5}\right)$ & $\beta_{5}=0.23^{* *}$ & $\beta_{5}=0.17^{* *}$ \\
\hline Possesses a driving license - $\left(Y_{1}\right)$ & $\gamma_{1}=-0.11^{*}$ & $\gamma_{1}=-0.14^{*}$ \\
\hline Indices of Goodness of fit Parameters & & \\
\hline
\end{tabular}




\begin{tabular}{|l|c|c|}
\hline Chi-sq. / DF & 2.447 & 2.397 \\
\hline GFI & 0.858 & 0.864 \\
\hline AGFI & 0.795 & 0.804 \\
\hline CFI & 0.810 & 0.819 \\
\hline RMSEA & 0.097 & 0.095 \\
\hline $\mathrm{R}^{2}$ & 0.25 & 0.29 \\
\hline
\end{tabular}

Note: $* * *$ Significant at $1 \%, * *$ significant at $5 \%, *$ significant at $10 \%$

This study adds some new dimension of students' mode choice behavior in comparison to previous similar studies e.g. freedom and flexibility in traveling, possession of a driving license, and bus trend attitudes (Soman and Verghese, 2019; Kotoula et al., 2018; Nasrin, 2017, Das et al. 2016; Bicikova, 2014). It is well understood that private transport offers a better level of freedom and flexibility and comfort in travel and are the barriers to enhancing the use of university bus service (Belwal, 2013). It is perceived from the SCT factor that the generalized travel cost with the bus is higher than the private car, which makes the university bus unfavorable to use for some of the students. Individual's safety and privacy are also contributing factors in mode choice behavior in the context of Oman (Belwal, 2013). Results imply that there is a need to develop and encourage transit-oriented and pro-social attitudes among students. Students' should aware of the negative impacts of increased traffic demand with more use of the private vehicle. The students' who feel more obligations to protect the environment, society, and natural resources would have more willingness to use the bus service. Those students who are more social and like to interact with friends and passengers would prefer to use the bus service (Javid et al., 2016). These findings imply that specific service quality attributes and student's travel attitudes and intentions are important in developing an effective transport service for the students.

\section{CONCLUSIONS AND IMPLICATIONS}

This paper attempted to identify significant service quality attributes of traveling modes in the context of Oman considering perceptions of university students. Around $50 \%$ of the students have a personal car, and around $35 \%$ possess a driving license. The number of students who use the university bus (57\%) is higher than the number of students who use private cars. Relaxed traveling, safety during the traveling, and travel time saving are the most important attributes of service quality for most of the students. The driving task usually results in stress on the drivers and risky driving behavior. On the other hand, traveling on a bus provides more relaxed and safe traveling in comparison to private transport. The factors of SCT, FFT, SPT, CA, and BA are significant in determining the students' travel attitudes toward the university bus service. Traveling in a car is more comfortable and provides more freedom and flexibility in traveling than a bus. The results revealed that the use of bus tends to increase travel time and reduce the freedom and flexibility in traveling. The university bus is unreliable in comparison to the car, but it provides an opportunity for students to interact with other travelers and friends on a bus. More than $50 \%$ of the students agreed that we should use a university bus for the reduction of traffic demand and consumption of natural resources. The students who possess bus-oriented travel attitudes would prefer to use a bus in the future for the reduction in traffic congestion and the consumption of natural resources. However, this trend is the opposite for those students who believe in car-oriented attitudes. Students' safety and privacy in traveling are also important factors that are required to consider while developing public transport policies for the students.

There is a need to improve the reliability and punctuality of the university bus service as unreliability causes delays in the arrival of students at the campus. As some students prefer to use the bus service because it provides relaxed traveling. The improvement in its service would help in enhancing the use of the bus. The students' intentions to use bus service for environmental and social reasons help in deriving the sustainable transportation policies that 
should focus on developing pro-social travel attitudes and norms among students. There is a need to develop and promote transit-oriented attitudes among students for the effective use of university bus service. This can be done through the intervention of some soft and incentive policies. For example, students should be aware of the benefits of using public transport and it can be done through awareness and behavioral change programs. Also, some economic incentives on the use of the bus in comparison to a private car would help in promoting the use of bus among students. This study only considered the perceptions of students in identifying the important factors influencing the mode choice behavior. For this purpose, a university bus service and private car travel alternatives have been considered in the evaluation. Future studies should include a large sample size comprising of different segments (e.g., students, employees, the general public.) of the travel market for evaluation of service quality of all available travel alternatives. There is a need to include the financial, economic, and user's affordability dimensions of traveling while evaluating the factors influencing travel behavior. Future studies should also focus on the development of the mode choice model using a stated preference questionnaire survey approach where important service quality attributes must be considered. These important service quality attributes include travel time, travel cost, reliability, convenience, and comfort. A stated preference experiment can help in providing a good understanding of anticipated factors of people's travel mode choice. The theoretical concept of behavioral theories may be applied in assessing the social-cognitive aspects of travel behavior. Despite limitations, the derived findings have significant implications to derive suitable and effective public transport policies.

\section{ACKNOWLEDGMENT}

The authors acknowledge the support and cooperation of the respondents in recording their responses to achieve the objectives of this research. The authors are also thankful to all other people who helped in the data collection.

\section{REFERENCES}

Anable, J. 2005. 'Complacent car addicts' or 'aspiring environmentalists'? Identifying travel behaviour segments using attitude theory. Transport Policy 12 (1):65-78.

Assi, K.J., Nahiduzzaman, K.M., Ratrout, N.T. \& Aldosary, A.S. 2018. Mode choice behavior of high school goers: Evaluating logistic regression and MLP neural networks. Case Studies on Transport Policy 6(2):22530.

Beirao, G. \& Cabral, J.A.S. 2007. Understanding attitudes towards public transport and private car: A Qualitative Study. Transport Policy 14: 478-89.

Belwal, R. 2013. People's Perception of Public Transport Services in Oman. Jurnal Teknologi 65(3): 9-16.

Belwal, R., Minhans, A., \& Al-Balushi, A.M. 2013. Perception of Taxi Services in Oman-A Cross Examination of Citizens' and Taxi Drivers' Perception. Jurnal Teknologi 65(3): 33-39.

Bentler, P.M., \& Bonett, D.G. 1980. Significance tests and goodness of fit in the analysis of covariance structures. Psychological Bulletin 88(3): 588-606.

Bicikova, K. 2014. Understanding Student Travel Behavior: A Segmentation Analysis of British University Students. Journal of Travel \& Tourism Marketing 31(7): 854-67.

Boomsma, A., and Hoogland, J. J. 2001. The Robustness of LISREL Modeling Revisited. In R. Cudeck, S. du Toit, \& D. Sörbom (Eds.), Structural Equation Models: Present and Future. A Festschrift in Honor of Karl Jöreskog (pp. 139-168). Lincolnwood, IL: Scientific Software International.

Cattaneoa, M., Malighettia, P., Morlottia, C., \& Paleari, S. 2018. Students' mobility attitudes and sustainable transport mode choice. International Journal of Sustainability in Higher Education, 19(5):942-62. 
Daisy, N.S., Hafezi, M.H. Liu, L. \& Millward, H. 2018. Understanding and Modeling the Activity-Travel Behavior of University Commuters at a Large Canadian University, Journal of Urban Planning and Development 144(2):04018006.

Das, R., Kumar, S.V., Prakash, B., Dharmik \& Subbarao, S.S.V. 2016. Analysis of University Students Travel Behaviour: En-Route to Sustainable Campus. Indian Journal of Science and Technology 9(30): 1-6.

Field, A. 2013. Discovering Statistics Using SPSS (4th ed.). SAGE Publications.

Golob, T.F. 2001. Joint models of attitudes and behaviour in the evaluation of the San Diego I-15 Congestion Pricing Project. Transportation Research Part A: Policy and Practice 35: 495-514.

Guzman, M.P.D. \& Diaz, C.E. 2005. Analysis of mode Choice Behavior of Students in Exclusive Schools in Metro Manila: The Case of Ateneo De Manila University \& Miriam College. Proceedings of the Eastern Asia Society for Transportation Studies 5: 1116-31.

Haider, R., Yasar, A., \& Tabinda, A.B. 2018. Impact of transport sustainability on air quality in Lahore, Pakistan. Current Science 114(11): 2380-86.

Henning, E., Schubert, T.F. \& Maciel, A.C. 2020. Modelling of University Student Transport Mode Choice in Joinville: a Binary Logistic Model for Active Modes. Journal of Sustainable Development of Energy, Water, and Environment Systems 8(4): 678-91.

Hooper, D., Coughlan, J. \& Mullen, M.R. 2008. Structural Equation Modelling: Guidelines for determining model fit. Electronic Journal of Business Research Methods 6(1): 53-60.

Javid, M.A., Al-Hashmi, W.Y. \& Al-Shaqsi, A.S. 2020. Exploring the Student's Perceptions on Safety Aspects of the University of Nizwa Bus Service in Oman. Iranian Journal of Science and Technology, Transactions of Civil Engineering. https://doi.org/10.1007/s40996-020-00545-z

Javid, M.A., Okamura, T., \& Nakamura, F. 2015a. Evaluation of Public Satisfaction with Service Quality of Daewoo Urban Bus Service in Lahore, Pakistan. Journal of the Eastern Asia Society for Transportation Studies 11:1097-1108.

Javid, M.A., Okamura, T., Nakamura, F., Tanaka S. \& Wang, R. 2015b. Factors Influencing the Acceptability of Travel Demand Management (TDM) Policies in Lahore: Application of Behavioral Theories. Asian Transport Studies (ATS) 3(4): 447-66.

Javid, M.A., Okamura, T., Nakamura, F., Tanaka S. \& Wang, R. 2016. People's Behavioral Intentions towards Public Transport in Lahore: Role of Situational Constraints, Mobility Restrictions, and Incentives. KSCE Journal of Civil Engineering 20(1): 401-10.

Khattak, A., Wang, X., Vandecar-Burdin, T., \& Wilson-John, W. 2011. “Old Dominion University student travel survey." Final Report, Old Dominion University, Norfolk, VA.

Kline, R.B. 2005. Methodology in the social sciences. Principles and practice of structural equation modeling $\left(2^{\text {nd }}\right.$ Ed.). Guilford Press.

Klöckner, C.A. \& Friedrichsmeier, T. 2011. A multi-level approach to travel mode choice - How person characteristics and situation-specific aspects determine car use in a student sample. Transportation Research Part F: Traffic Psychology and Behaviour 14(4): 261-77.

Kotoula, K.M., Sialdas, A., Botzoris, G., Chaniotakis, E. \& Grau, J.M.S. 2018. Exploring the Effects of University Campus Decentralization to Students' Mode Choice. Periodica Polytechnica Transportation Engineering 46(4): 207-14.

Limanond, T., Butsingkorn, T. \& Chermkhunthod, C. 2011. Travel behavior of university students who live on campus: A case study of a rural university in Asia. Transport Policy 18(1): 163-71. 
Maneesh, M., Selvarag, R., Shamanth, K., Sunil, P. \& Mark, W.B. 2007. Examination of Student travels mode choice. Transportation Research Board, $86^{\text {th }}$ Annual Meeting, Location: Washington DC, United States, 2007-1-21 to 2007-1-25.

McLoughlin, P. 2016. "Gulf States put brakes on joint-GCC railway plan", https://www.alaraby.co.uk/english/indepth/2016/5/4/gulf-states-put-brakes-on-joint-gcc-railway-plan. Accessed July 15, 2016.

Nasrin, S. 2017. Private University Students Mode Choice Behaviour for Travel to University: Analysis in the Context of Dhaka City. $4^{\text {th }}$ Conference on Transportation Research Group of India, Indian Institute of Technology, Bombay, IIT Bombay, Mumbai, India, At Mumbai, India.

Raykov, T. \& Marcoulides, G.A. 2000. A first course in structural equation modeling, Mahwah, NJ: Erlbaum.

Ripplinger, D., Hough, J. \& Brandt-Sargent, B. 2009. The Changing Attitudes and Behaviors of University Students toward Public Transportation: Final Report, Small Urban \& Rural Transit Center Upper Great Plains Transportation Institute North Dakota State University Fargo, North Dakota.

Romanowska, A., Okraszewska, R. \& Jamroz, K. 2019. A Study of Transport Behaviour of Academic Communities. Sustainability 11: 3519. DOI: 10.3390/su11133519.

Schreiber, J.B., Stage, F.K., King, J., Nora, A. \& Barlow, E.A. 2006. Reporting structural equation modeling and confirmatory factor analysis results: A review. Journal of Educational Research 99(6): 323-38.

Shaaban, K. \& Kim, I. 2016. The influence of bus service satisfaction on university students' mode choice. Journal of Advanced Transportation 50: 935-48.

Somon, J. \& Verghese, V. 2019. Mode choice Behavior Analysis of Students in Thrissur city. International Research Journal of Engineering and Technology 6(6): 1226-31.

Steg, L. 2005. Car use: lust and must. Instrumental, symbolic and affective motives for car use. Transportation Research Part A: Policy and Practice 39(2-3): 147-62.

Taber, K.S. 2017. The Use of Cronbach's Alpha When Developing and Reporting Research Instruments in Science Education. Research in Science Education. https://doi.org/10.1007/s11165-016-9602-2

Volosin, S.E. 2014. A Study of University Student Travel Behavior. ARIZONA STATE UNIVERSITY, December 2014.

Whalen, K., Paez, A., \& Carrasco, J.A. 2013. Mode choice of university students commuting to school and the role of active travel. Journal of Transport Geography 31: 132-42.

Zhou, J. 2012. Sustainable commute in a car-dominant city: Factors affecting alternative mode choices among university students. Transportation Research Part A: Policy and Practice 46(7): 1013-29.

Zhou, J. 2016. Proactive sustainable university transportation: Marginal effects, intrinsic values, and university students' mode choice. International Journal of Sustainable Transportation 10(9): 815-24. 